\title{
Communication and sustainability science teams as complex systems
}

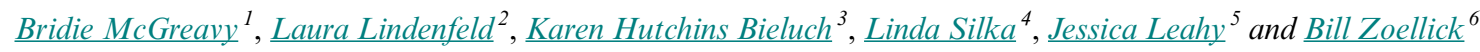

\begin{abstract}
Communication is essential to resilience, as interactions among humans influence how social-ecological systems (SES) respond to change. Our research focuses on how specific communication interactions on sustainability science teams, such as how people meet with each other; the ways in which they categorize themselves and others; the decision-making models they use; and their communication competencies affect outcomes. We describe research from a two-year study of communication in Maine's Sustainability Solutions Initiative, a statewide network of sustainability science teams. Our results demonstrate that decision making and communication competencies influenced mutual understanding, inclusion of diverse ideas, and progress toward sustainability-related goals. We discuss our results in light of key resilience themes and conclude with recommendations for communication design in sustainability teams for improved collaborative process and outcomes.
\end{abstract}

Key Words: communication; interdisciplinary collaboration; public participation in scientific research; resilience; Structuration Theory; sustainability science

\section{INTRODUCTION}

The resilience of social-ecological systems (SES) is influenced by interactions among humans and between humans and material environments. Sustainability science and public participation in science programs that have emerged in recent decades build on the premise that improving connections among humans and environments can contribute to resilience and adaptability (Kates et al. 2001, Jordan et al. 2012). However, the degree and quality of connections in these systems matter too (Adger et al. 2005, Folke et al. 2005, Shirk et al. 2012) because the ability to respond to change relies partially on adaptive capacities like learning (Pahl-Wostl et al. 2008, Ballard and Belsky 2010). Previous approaches to studying interactions within SES have largely adopted an information-based model of human communication (Lebel et al. 2006, Pahl-Wostl 2006, Mitchell 2009, Janssen 2013). Our communication research extends this systems perspective to include communication structures, processes, and outcomes that recursively create systems. Our model includes information exchange but also sees communication as a more complex and dynamic set of interactions. This expanded focus enables us to identify SES components that contribute to overall resilience.

We describe research from a two-year study of communication in Maine's Sustainability Solutions Initiative (SSI), a statewide network of sustainability science teams. This research was guided by two primary objectives. First, we sought to understand how communication within sustainability science teams influences outcomes related to learning and progress toward goals. Second, we wanted to contribute to understandings of how system properties promote SES resilience.

\section{COMMUNICATION BEYOND INFORMATION EXCHANGE IN AN SES}

Approaching communication as a complex system emphasizes part to whole relationships in which interactions produce a sum greater than individual parts (Monge 1977, Ramage and Shipp 2009). This work builds on an extensive body of literature that approaches social arrangements as systems (Folke et al. 2005, Norberg and Cumming 2008, Stokols et al. 2013). Folke et al.
(2005) describe collaborative governance as "the structures and processes by which people in societies make decisions and share power" (Folke et al. 2005:444). This systems perspective assumes that, through structure and process, people simultaneously participate in and create the systems of which they are a part.

\section{System as structure, process, and outcomes}

We distinguish between communication structures, processes, and outcomes, recognizing that these system dimensions are interrelated and mutually influencing (see Table 1 for additional term definitions). These dimensions interact to guide emergent patterns of order at individual, team, organizational, and SES scales. The notion that we never step into the same river twice applies to understanding communication as system; we refer to this dynamic as recursivity.

We define communication structures as symbolic and material configurations that guide how people interact (Giddens 1984, Folke et al. 2005, Stokols et al. 2013). Stokols et al. (2013) refer to language-based frames as semiotic structures and they describe how these interact with material structures. Semiotic structures include categorical typologies such as "stakeholder" and "researcher" or what is labelled "right" as a course of action. Openly negotiating structural frame differences can help identify and promote agreed-upon structures (Dewulf et al. 2007). In our use, material structures include funding allocation, meeting strategies, and levels and frequencies of interaction. Together, semiotic and material communication structures define the degree of participation on teams (Shirk et al. 2012).

Processes refer to capacities and resources on which people draw in interactions (Giddens 1984, Folke et al. 2005). Processes within communication systems include decision making (Norton 2007), communication competencies (Thompson 2007, 2009), and motivations and identity formation (Morgan 1997, Schneider and Somers 2006). Following the recursive model, structures create possible channels for interaction. Processes are the spaces of interaction that occur within but that also continually reproduce the channels (Giddens 1984, Poole and McPhee 2005).

\footnotetext{
${ }^{1}$ New England Sustainability Consortium, University of Maine, ${ }^{2}$ Margaret Chase Smith Policy Center \& Communication \& Journalism, University of Maine, ${ }^{3}$ Dartmouth College, ${ }^{4}$ Senator George J. Mitchell Center for Sustainability Solutions, University of Maine, ${ }^{5}$ School of Forest Resources, University of Maine, ${ }^{6}$ Schoodic Institute at Acadia National Park
} 
Table 1. Glossary of communication systems terms.

\begin{tabular}{|c|c|}
\hline Term & Definition \\
\hline $\begin{array}{l}\text { Communication } \\
\text { as complex } \\
\text { system }\end{array}$ & $\begin{array}{l}\text { Assumes that, through communication, people } \\
\text { simultaneously participate in and create the social } \\
\text { systems (like teams and organizations) in which } \\
\text { they are also a part. More broadly, a systems } \\
\text { perspective emphasizes the part to whole } \\
\text { relationship in which the system emerges through } \\
\text { interactions among human and nonhuman actors } \\
\text { that continually shape patterns of social and } \\
\text { ecological order. }\end{array}$ \\
\hline Recursivity & $\begin{array}{l}\text { Etymologically refers to patterns that "run } \\
\text { throughout" a system. Assumes that systems } \\
\text { contain the seeds for their growth and renewal in } \\
\text { which structure and process mutually interact to } \\
\text { shape dynamically unfolding patterns of order. } \\
\text { Although recursivity implies dynamic equilibrium, } \\
\text { it is more appropriately visualized as a fractal } \\
\text { pattern of self-similarity across scales of } \\
\text { organization than as an attractor or basins model } \\
\text { of change. }\end{array}$ \\
\hline Feedback & $\begin{array}{l}\text { Communication that occurs as information } \\
\text { exchange. }\end{array}$ \\
\hline Structure & $\begin{array}{l}\text { Symbolic and material parts of a system that create } \\
\text { the framework or draw the boundaries around } \\
\text { which social interactions occur. This is analogous } \\
\text { to Giddens' (1984) concept of "rules" in social } \\
\text { formation. }\end{array}$ \\
\hline Process & $\begin{array}{l}\text { Capacities and resources on which people draw in } \\
\text { their interactions to shape social formations. A } \\
\text { useful analogy that considers the relationship } \\
\text { between structure and process is that of a house. } \\
\text { The structure includes the foundation and walls } \\
\text { and processes guide how we live out our lives } \\
\text { within those confines (Poole and McPhee 2005). }\end{array}$ \\
\hline $\begin{array}{l}\text { Semiotic } \\
\text { structures }\end{array}$ & $\begin{array}{l}\text { Semiotics studies how signs point toward specific } \\
\text { and socially agreed upon meanings. Signs, like } \\
\text { words, frames, typologies, visual imagines, are } \\
\text { material entities that reproduce meanings within a } \\
\text { society. Signs are not fixed points of reference to } \\
\text { stable entities. For example, the term "stakeholder" } \\
\text { can mean two different things to individuals on } \\
\text { teams depending on their respective societies, } \\
\text { disciplines, or other social domains. }\end{array}$ \\
\hline $\begin{array}{l}\text { Material } \\
\text { structures }\end{array}$ & $\begin{array}{l}\text { Physical entities or resources that shape } \\
\text { participation, such as funding allocation, meeting } \\
\text { strategies, and levels and frequencies of interaction } \\
\text { as patterns of action. Although semiotic structures } \\
\text { are material, and the materials we describe rely on } \\
\text { signs for their description, we differentiate these } \\
\text { two parts of the system to provide specific points of } \\
\text { focus for studying and making decisions about } \\
\text { teams as complex systems. }\end{array}$ \\
\hline
\end{tabular}

Our analysis of outcomes emphasizes effective interdisciplinary integration (Dewulf et al. 2007, Miller et al. 2008), social learning (Pahl-Wostl 2006, Jordan et al. 2012), and progress toward sustainability goals (Kates et al. 2001). This emphasis is informed by objectives within sustainability science, public participation in science, and resilience literatures.

\section{Application to interdisciplinary collaboration and public participation}

Previous communication studies have focused on processes, structures, and outcomes associated with interdisciplinary teams (Thompson 2007, 2009, Fraser and Schalley 2009, McGreavy et al. 2013). Different types of interactions influence how objectives are achieved and the quality of interpersonal relationships (Thompson 2009). Demonstrating presence, laughing together, and active listening can improve the quality and outcomes of participation. In contrast, sarcasm, blatant boredom, and power struggles inhibit efficacy and capacity (Thompson 2009). Described as collective communication competencies, these practices have been shown to be essential for successful interdisciplinary collaboration (Fraser and Schalley 2009, Thompson 2009).

Discussions of public participation draw from communication systems perspectives to promote specific outcomes, like environmental policy (Daniels and Walker 2001, Senecah 2004, Norton 2007). Several studies demonstrate that effective public participation relies on adequate access to information, standing in participatory processes, and influence within decision making (Depoe et al. 2004, Senecah 2004, Walker et al. 2006). Decision making refers to spaces of interaction that create or constrain participation on a team (Norton 2007). In this view, when a single person on a team is positioned as the primary decision maker, we consider that a space of action that forecloses others' access to that space.

\section{Resilience thinking}

Resilience is a way to think about adaptive capacities, transformability, and sustainability (Walker et al. 2004, Folke et al. 2010, Goldstein 2012). SES are resilient to the extent that they can respond to external drivers and adjust internal processes to allow for development along an intended path (Adger et al. 2005). Resilience thinking enables us to understand social interactions' influence on collective abilities to maintain or transform systems.

Systems theories of communication contribute to three key resilience lenses that can advance thinking about adaptive capacity: (1) the system's structures and processes supporting diversity and learning; (2) its recursive properties; and (3) evidence of emergent patterns of order. Resilience grapples with how to study and make strategic interventions in patterns of order across scale (Gunderson and Holling 2001, Miller et al. 2008). Applying these lenses leads to our primary research question: How do we evaluate and strategically change communication within teams to promote sustainability outcomes? Related to this overarching question, we ask:

1. Structure: What are the semiotic and material structures within teams?

2. Process: How do teams make decisions? What are their collective communication competencies? What are team members' motivations and identities?

3. How do structures and processes influence outcomes, such as learning and progress toward stated goals?

We describe our results and then discuss these points to address our primary question about how, through teams, we may recursively guide the emergence of sustainability. 
Table 2. Degree of participation by stakeholder typology and category, level of involvement $(1=$ Not involved, $2=$ Somewhat involved, 3 = Involved, 4 = Very involved), frequency of contact, and communication media ("all other" includes video, phone, and/or conference call, technical reports and/or newsletters, project or research web site, and blogs).

\begin{tabular}{|c|c|c|c|c|c|c|c|c|c|c|}
\hline \multicolumn{2}{|c|}{ Stakeholder Typology and Category } & \multicolumn{3}{|c|}{ Level } & \multicolumn{2}{|c|}{$\begin{array}{l}\text { Communication } \\
\text { Frequency } \\
\end{array}$} & \multicolumn{4}{|c|}{ Media (\%) } \\
\hline & & $\mathrm{N}$ & Mean & $\mathrm{SD}$ & $\mathrm{N}$ & Mode & Total & Face & E-mail & All other \\
\hline \multicolumn{2}{|c|}{ More than human world } & 59 & 2.5 & 1.3 & 34 & Don’t know & $\sim$ & $\sim$ & $\sim$ & $\sim$ \\
\hline Society & Future generations & 72 & 2.3 & 1.1 & 44 & Don’t know & $\sim$ & $\sim$ & $\sim$ & $\sim$ \\
\hline \multirow[t]{4}{*}{ Institution: } & NSF/EPSCoR & 71 & 2.4 & 1 & 50 & Annually & 55 & 11 & 24 & 66 \\
\hline & SSI & 77 & 3 & 0.9 & 69 & Monthly & 108 & 36 & 43 & 21 \\
\hline & University & 73 & 2.1 & 1 & 43 & Quarterly & 65 & 39 & 46 & 15 \\
\hline & Dept. colleagues & 82 & 2 & 1 & 45 & Monthly & 88 & 49 & 49 & 2 \\
\hline \multirow{9}{*}{$\begin{array}{l}\text { Team \& } \\
\text { Community: }\end{array}$} & Federal agencies & 79 & 2.1 & 1.1 & 42 & Quarterly & 68 & 21 & 43 & 37 \\
\hline & Individual citizens & 82 & 2.6 & 1 & 65 & Quarterly & 35 & 54 & 29 & 17 \\
\hline & $\mathrm{K}-12$ & 76 & 1.6 & 0.9 & 30 & Never & 92 & 37 & 35 & 28 \\
\hline & Municipal officials & 82 & 2.8 & 1.1 & 63 & Quarterly & 19 & 74 & 16 & 11 \\
\hline & NGOs & 78 & 2.7 & 1 & 62 & Quarterly & 99 & 41 & 37 & 21 \\
\hline & Private sector & 79 & 2.3 & 1 & 54 & Annually & 83 & 40 & 35 & 25 \\
\hline & State agencies & 80 & 2.8 & 1 & 63 & Monthly & 111 & 33 & 43 & 2 \\
\hline & Tribal communities & 78 & 1.5 & 0.9 & 18 & Don't know & 17 & 47 & 35 & 18 \\
\hline & Cooperative Extension & 82 & 1.8 & 0.9 & 36 & Monthly & 57 & 37 & 47 & 16 \\
\hline Team & Researchers on SSI & 79 & 2.5 & 1 & 62 & Weekly & 105 & 49 & 47 & 5 \\
\hline Individual & Self & 83 & 3.7 & 0.7 & 68 & Daily & $\sim$ & $\sim$ & $\sim$ & $\sim$ \\
\hline
\end{tabular}

\section{METHODS}

Maine's Sustainability Solutions Initiative

We studied interdisciplinary collaboration and stakeholder engagement within Maine's Sustainability Solutions Initiative (SSI). This five-year, \$20 million National Science Foundation (NSF)-funded project involved 11 Maine universities and colleges, over 150 faculty and students in $20+$ disciplines across biophysical and social sciences, and stakeholders from diverse institutions. The 20 project teams focused on SES issues related to water and urbanization, climate and energy, and forest management. The Maine Tidal Power Initiative team exemplifies SSI's approach to produce use-inspired research. This team involved multiple disciplines, e.g., engineers, marine biologists, and social scientists, and diverse stakeholders, such as, state and federal regulators, tidal power developers, and fishermen (Johnson and Zydlewski 2012). Researchers Johnson and Zydlewski (2012:63) note that creating spaces where community members could ask questions and receive project updates was "key to allowing productive dialogue and decision-making about the risks and benefits of tidal power." They also worked with fishermen to identify important habitat areas to avoid in the deployment of the turbine. The ways in which they involved the public in their science led to successful installment of a tidal power turbine in Cobscook Bay. This team demonstrates the sustainability science approach that was intended for all SSI teams. Our research sought to understand the emergent patterns within teams to understand why some teams made progress in key areas while other teams did not.

\section{RESEARCH DESIGN AND ANALYSIS}

We employed a mixed-methods research design in four phases: (1) ongoing participant observations; (2) qualitative interviews (n $=41)$; (3) an online survey $(n=156)$; and (4) member-checking interviews with key informants $(\mathrm{n}=5)$ to ground-truth observations (Creswell 2003). The mixed methods approach allowed for rich qualitative insights about individual experiences and subsequent analysis of how these experiences generalized within the organization. Our sequential mixed methods design also used qualitative results to inform the development of our survey (Creswell 2003).

For our qualitative research, we conducted participant observations at all organizational events and meetings. The first author took detailed field notes from October 2010 through May 2013. We interviewed 41 faculty members and graduate students using a purposive sampling strategy that invited participation from the University of Maine and University of Southern Maine researchers who serve as SSI's research hubs. Most interviews were conducted in January through July 2011 and lasted approximately one hour. Audio recordings were fully transcribed, resulting in more than 600 pages of single-spaced transcripts. We used modified grounded theory with stages of inductive content analysis to code interviews in multiple rounds of coding and triangulation (Corbin and Strauss 2008).

We conducted an online survey using Qualtrics of a comprehensive sample of participants in the network $(n=156$; Dillman 2007). The survey consisted of 26 questions that used 5point Likert scale, preference ratings, and text boxes and took approximately 20 minutes. Survey questions asked participants about team decision making, communication, and motivations for stakeholder involvement in research (see Tables 2-4 for questions). The online survey was active in July and August 2012, and data were analyzed using the Statistical Package for Social Sciences (SPSS) Version 19 (IBM Corporation, Armonk, New York, USA).

We created a summative scale of communication competence variables and tested the internal reliability using Cronbach's alpha (Vaske 2008). We used Pearson correlation analyses to describe 
associations among variables. We also conducted an exploratory Principal Components Analysis (PCA) with a varimax orthogonal rotation on a set of questions that explored researcher motivations (Hair et al. 2010). We used the Kaiser criterion to select components with eigenvalues $\geq 1.0$, and we used a multistep process of interpretation to identify and retain components (Hair et al. 2010) with listwise deletion for all missing data (Vaske 2008). We used participant observations and interviews with key informants $(n=5)$ to member check our interpretations (Patton 2002).

\section{RESULTS}

We inductively identified 21 interview codes, including decision making and meeting strategies, typologies, challenges, and opportunities within collaboration, and motivations and identities related to partnership formation. We achieved a 56\% (n $=88$ ) response rate for the online survey with at least one respondent from every SSI team (22 total). Forty-five percent of respondents indicated a primary institutional affiliation with social sciences, 36\% with biophysical sciences, and $19 \%$ with administrative, engineering, humanities, and other self-identified affiliations such as environmental and marine sciences.

\section{Semiotic and material structures}

What are the typologies?

In the interviews, participants' descriptions of collaborators and stakeholders followed a nested typology (Table 2), as summarized by one participant:

The first set of stakeholders is the people I work with, the team itself. And then other folks who are involved with the SSI project, and then other folks that are complementary to the University institutional functioning. I didn't anticipate thinking of them as stakeholders, but you kind of have to. Concentric circles outward is how I think of stakeholders. To be human means that you live on this earth, you breathe air, and drink water. Those are the stakeholders that I see that are ... human and morethan-human.

Participants routinely described stakeholders in these terms, starting at individual level and moving outward to include institutions such as SSI, the University of Maine, and NSF; community groups; society and future generations; and the morethan-human-world.

\section{What are the material structures?}

Participants described several material structures on their teams, most notably the funding allocation; geographic distance between campuses; time intensiveness of collaboration; and restrictive tenure and promotion review systems. Of these, funding was a primary concern, as participants described how funding shaped their collaboration, as demonstrated by the following quote:

There is this complicating factor that the budget is split between [these two campuses] and the [other campus'] budget was negotiated from the start in a very different way. So it's a reality of university politics or just design organization, but it does influence decision making 'cause it's there in the background. Their budget was negotiated at the outset of the project for five years. That's a very different working environment than the rest of us on my campus' side.
In SSI, funding was a material structure that influenced processes like decision making and other project-related activities. The following questions posed in one interview demonstrate the need to describe material structures and subsequent patterns of action that guide the degree of participation:

How much do we have to meet? How much do we have to talk? How much do we have to hang out in order to get at the level where we can work together effectively and trust one another and not have the typical gamesmanship?

We used the stakeholder typology to gauge levels of involvement with stakeholders. Participants reported high levels of involvement with municipal officials $(\mathrm{M}=2.8, \mathrm{SD}=1.1)$, state agencies $(\mathrm{M}=2.8, \mathrm{SD}=1.0)$, and nonprofit organizations $(\mathrm{M}=$ $2.7, \mathrm{SD}=1.0)$. Our results on communication frequency demonstrated that researchers were in contact with key stakeholders on a monthly or quarterly basis. Researchers reported that most interactions occurred face-to-face or through e-mail, demonstrating a key technology that structured communication. The following quote illustrates the interaction of semiotic and material structures:

\section{[When our team first met] we sat around for two or three hours and we just talked about why does [your discipline] do it this way? And we were comparing notes. You guys do this and I've done that ... but am I doing it right? That sort of thing.}

This participant described their initial meeting as being face-toface for two to three hours. At this meeting, i.e., within the material structure, they began to negotiate the semiotic structure of what was "right" on their team.

\section{Processes: resources and capacities drawn on in interaction}

How do teams make decisions?

By using relative interview coding frequency, we identified five primary decision-making models, including consensus-based (63\%), problem-project specific $(49 \%)$, core group involving 3-4 people $(49 \%)$, single person decision maker $(34 \%)$, and no decision-making structure $(2 \%)$. Most SSI teams used a consensus-based or problem-project specific model of decision making, creating space to talk about perspectives and work through differences. Many teams described employing more than one decision-making strategy:

We get together for meetings or through email, come to a consensus usually. It is pretty driven by that rather than one person making a decision, unless it is something silly and small. And the reason for that is because it's a combination of divergent interests so not any one person can [make all the decisions]. Remote sensing people are much better at making decisions about remote sensing than I am, as an example.

This participant described both consensus-based and problemproject specific models. They also described face-to-face meeting strategies, a structural characteristic. In contrast, the single person decision-making strategy is exemplified in the quote: "[For this team], I'm the primary decision maker. I try and protect the CoPI's. Grad students carry out the work."

In cases where teams primarily used single person decision making, interview participants expressed frustration with lack of 
Table 3. Correlations among process variables, including decision making and collective communication competence (CCC), and outcome variables including mutual understanding of goals, idea inclusion, and satisfaction with stakeholder engagement. Participants were asked to rate their level of agreement or disagreement with statements $(1=$ Strongly disagree and $5=$ Strongly agree $)$.

\begin{tabular}{|c|c|c|c|c|c|c|}
\hline & & & & Mutual Understanding & $\begin{array}{c}\text { Ideas } \\
\text { Included }\end{array}$ & $\begin{array}{l}\text { Engagemen } \\
\text { Satisfaction }\end{array}$ \\
\hline & $\mathrm{N}$ & Mean & $\mathrm{SD}$ & $\begin{array}{l}(\text { Mean }=4.1 \\
\text { SD 1.03) }\end{array}$ & $\begin{array}{c}(\text { Mean }=4.3 \\
\text { SD 0.78) }\end{array}$ & $\begin{array}{c}(\text { Mean }=3.7 \\
\text { SD 1.1) }\end{array}$ \\
\hline $\begin{array}{l}\text { Decision Making: } \\
\text { I am very involved in the decision making } \\
\text { on my team. }\end{array}$ & 82 & 4.01 & 1.09 & $0.50^{* *}$ & $0.81 * *$ & $.25^{*}$ \\
\hline CCC Summative scale $(\alpha=0.69)$ & 82 & 24.71 & 3.78 & $0.64 * *$ & $0.66^{* *}$ & $0.45 * *$ \\
\hline CCC Scale with variables & 82 & 4.12 & 0.63 & $\sim$ & $\sim$ & $\sim$ \\
\hline $\begin{array}{l}\text { 1. My team members communicate well } \\
\text { with each other. }\end{array}$ & 82 & 4.10 & 0.98 & $0.62 * *$ & $0.52 * *$ & $0.39 * *$ \\
\hline $\begin{array}{l}\text { 2. My team rarely shows respect for } \\
\text { diverse opinions. }\end{array}$ & 82 & 1.88 & 1.24 & -0.17 & -0.03 & -0.01 \\
\hline $\begin{array}{l}\text { 3. My team laughs or uses humor } \\
\text { frequently. }\end{array}$ & 82 & 4.28 & 0.82 & $0.36^{* *}$ & $0.33 * *$ & $0.33 * *$ \\
\hline 4. My team rarely discusses outcomes. & 82 & 1.99 & 0.99 & $-0.43^{* *}$ & $-0.51^{* *}$ & $-0.39^{* *}$ \\
\hline $\begin{array}{l}\text { 5. My team actively works to build a } \\
\text { common language. }\end{array}$ & 82 & 3.90 & 0.87 & $0.50^{* *}$ & $0.48 * *$ & $0.38 * *$ \\
\hline
\end{tabular}

**Correlations significant at the 0.01 level (2-tailed).

*Correlation significant at the 0.05 level (2-tailed).

access to decision space and lower satisfaction with overall process.

\section{What are teams' communication competencies?}

Participants described a high degree of communication competence: members demonstrated respect, trust, and listening. They avoided negative sarcasm, power jockeying, and demonstrating boredom. Participants identified humor as important in their communication. This participant describes key dimensions of their communication competence, emphasizing shared decision making, mutual respect, and how they do not jockey for power:

\section{I think the only thing that is intentional and planned is that [the co-PI's] both have, there's complete mutual respect among the parties. We don't have this faculty versus grad student, which often does crop up. But in our group I've seen virtually no signs of that. I think because it's an environment of mutual respect. We don't think about it, we just go about and make decisions. Because of that we don't have anyone saying, "Well, I know better because I've been doing this longer." We don't really run into those issues at all.}

The survey results demonstrated that this pattern held across the organization because the mean communication competence score was 4.1 , indicating agreement that teams communicated well, showed respect for diverse opinions, and laughed together, among other features $(\mathrm{SD}=0.63, \alpha=0.69$; Table 3 ).

What are team members' motivations and identities?

We found that SSI members were motivated to work across disciplines and with stakeholders because they identified as sustainability scientists, needed to span boundaries, and were influenced by NSF funding. Researchers described several different identity-related dynamics. The following quotation demonstrates one researcher's identity as a sustainability scientist and how this relates to her motivation to collaborate:

In my view, you go back to some of the early writings by
Bill Clark, Nancy Dickson, even Cash to a certain extent,
where they say, "What is sustainability science? Well,
we're going to look at the dynamics of coupled natural
human systems. We're going to do work that is problem
oriented. And we're going to coproduce knowledge with
stakeholders." So, to me it's part of the definition. It's
what distinguishes sustainability science from some other
form of science. It's reconceptualizing science or how we
do research.

This participant described norms associated with sustainability science and integrated these norms into her identity as a researcher. The quantitative PCA results demonstrated this pattern of motivation and identity across SSI more broadly. The PCA identified six factors in researcher identities and motivations related to stakeholder engagement, including sustainability scientist identity $(\mathrm{e}=6.14, \mathrm{VAR}=29.25, \alpha=0.83)$, the need for boundary spanning $(\mathrm{e}=2.04$, VAR $=9.71, \alpha=0.78)$, and service to society $(\mathrm{e}=1.76$, VAR $=8.40, \alpha=0.66$; Table 4$)$. Other motivation factors included funding support and grant requirements, commitment to stakeholder rights and relationships, and departmental obligations.

Outcomes: mutual understanding, diverse ideas, progress

Qualitatively, we found that decision making and communication competencies affected how participants felt about the process, their ongoing commitment to collaborate, and eventual project outcomes like developing research methods, implementing new technologies, and enacting legislation. Interviews and participant observations revealed that teams using single person decision making experienced reduced individual satisfaction and slower or no progress toward goals. 
Table 4. Principal Components Analysis (PCA) of researcher motivations for stakeholder engagement. Participants were asked to rate how much they agreed or disagreed with the following statement: "I was motivated to engage stakeholders in my SSI project(s) because ..."

\begin{tabular}{|c|c|c|c|c|c|c|c|}
\hline & \multicolumn{7}{|c|}{ Rotated Component Matrix $^{\dagger}$} \\
\hline & 1 & 2 & 3 & 4 & 5 & 6 & Communality \\
\hline \multicolumn{8}{|l|}{ 1. Sustainability Scientist Identity, $\alpha=0.83$} \\
\hline ... they will help me be the kind of scholar I want to be. & 0.74 & 0.20 & 0.15 & 0.09 & 0.06 & 0.13 & 0.63 \\
\hline ... it makes my research relevant and locally appropriate. & 0.71 & 0.20 & 0.18 & 0.02 & 0.17 & -0.11 & 0.62 \\
\hline ... I want to help empower stakeholders to have a voice in the research. & 0.67 & 0.29 & 0.14 & 0.09 & 0.30 & 0.19 & 0.69 \\
\hline $\begin{array}{l}\text {... the partnership(s) ensure stakeholders' and researchers' needs are } \\
\text { met. }\end{array}$ & 0.52 & 0.45 & 0.32 & -0.16 & 0.09 & 0.12 & 0.63 \\
\hline $\begin{array}{l}\text { 2. Boundary Spanning, } \alpha=0.78 \\
\ldots \text { their involvement in this research is more likely to influence } \\
\text { individual and/or institutional action. }\end{array}$ & 0.28 & 0.76 & 0.13 & 0.08 & -0.07 & 0.03 & 0.69 \\
\hline ... I enjoy learning from people with different types of knowledge. & 0.22 & 0.71 & -0.02 & 0.04 & 0.24 & -0.12 & 0.63 \\
\hline $\begin{array}{l}\text {... it will help ensure the sustainability of the issue(s)/resource I study/ } \\
\text { care about. }\end{array}$ & 0.49 & 0.65 & 0.24 & -0.01 & -0.24 & -0.01 & 0.78 \\
\hline ... it will help resolve conflict among stakeholders. & 0.06 & 0.59 & 0.16 & -0.04 & 0.21 & 0.27 & 0.50 \\
\hline $\begin{array}{l}\ldots \text { of the satisfaction I experience from taking on interesting } \\
\text { challenges. }\end{array}$ & 0.38 & 0.49 & 0.08 & 0.15 & 0.40 & 0.04 & 0.57 \\
\hline \multicolumn{8}{|l|}{ 3. Service to Society, $\alpha=0.66$} \\
\hline ... I feel like I've failed if my research isn't used by society. & 0.21 & 0.11 & 0.81 & -0.22 & 0.10 & -0.03 & 0.77 \\
\hline ... I believe the issue I study is in a state of crisis. & 0.28 & -0.08 & 0.67 & 0.18 & -0.12 & 0.10 & 0.59 \\
\hline ... it will help me educate and train citizens, a central goal in my work. & 0.35 & 0.17 & 0.55 & 0.18 & 0.15 & 0.01 & 0.51 \\
\hline ... my colleagues brought them into the process. & -0.16 & 0.33 & 0.52 & 0.28 & 0.01 & 0.10 & 0.49 \\
\hline \multicolumn{8}{|l|}{ 4. SSI Funding Opportunity, $\alpha=0.62$} \\
\hline ... SSI requires me to include them. & 0.09 & -0.07 & -0.06 & 0.89 & 0.09 & 0.10 & 0.82 \\
\hline ... of the funding SSI provides. & 0.28 & 0.13 & 0.15 & 0.75 & -0.30 & -0.13 & 0.78 \\
\hline ... I have nothing to lose. & -0.28 & 0.11 & 0.28 & 0.51 & 0.20 & 0.14 & 0.49 \\
\hline \multicolumn{8}{|l|}{ 5. Rights and Relationships, $\alpha=0.65$} \\
\hline $\begin{array}{l}\text {... I don't have the right to exclude stakeholders from processes that } \\
\text { may impact them. }\end{array}$ & 0.18 & 0.05 & 0.14 & -0.03 & 0.85 & 0.14 & 0.79 \\
\hline $\begin{array}{l}\text { I. I really enjoy working with stakeholders. } \\
\text { 6. Departmental, } \alpha=0.62\end{array}$ & \multicolumn{6}{|c|}{ 6. Departmental, $\alpha=0.62$} & 0.59 \\
\hline ... my department required my participation. & -0.11 & 0.03 & 0.05 & 0.18 & 0.00 & 0.87 & 0.80 \\
\hline \multirow[t]{2}{*}{... it helps me bring on more graduate student. } & 0.27 & 0.07 & 0.10 & -0.10 & 0.12 & 0.81 & 0.77 \\
\hline & & & & & & & Totals \\
\hline Eigenvalues & 6.14 & 2.04 & 1.76 & 1.47 & 1.18 & 1.10 & 13.69 \\
\hline Percent of variance & 29.25 & 9.71 & 8.40 & 6.98 & 5.63 & 5.22 & 65.20 \\
\hline
\end{tabular}

${ }^{\top}$ Kaiser-Meyer-Olkin (KMO) Measure of Sampling Adequacy, 0.73; Bartlett's Test of Sphericity = 638.54, df 210, $\mathrm{n}=82$.

We tested relationships among process and outcomes statistically and found both decision making and communication competence strongly correlated with inclusion of diverse ideas $(r=0.81$ and $r=0.66$, respectively). Communication competence also strongly correlated with mutual understanding $(r=0.64)$.

\section{DISCUSSION}

Our results show how structures, like typologies and communication technologies, helped define and guide team participation in SSI. These structures interacted with processes, including decision making, communication competencies, and motivations and identities, to influence outcomes like mutual understanding, the inclusion of diverse perspectives, and progress toward goals. Qualitatively, we found that decision making and communication competence influenced collaboration satisfaction and progress toward goals. Quantitatively, decision making and communication competence were both strongly correlated with the inclusion of diverse ideas in the project. Communication competence was also strongly correlated with mutual understanding among team members.

We consider these results through our overarching research question, namely how do we evaluate and strategically change communication within teams to promote sustainability outcomes? Approaching communication as a complex system means that our strategies must align with this worldview. Resilience, with its extensive scholarship on complex systems, provides a heuristic for advancing recommendations that may be applied with sensitivity to complexity, context, and scale. When paired with communication as complex system, we can elaborate resilience lenses related to diversity and recursivity and apply these to a discussion of emergent patterns of order across organizational scales. We conclude with recommendations for communication design within teams as complex systems. 


\section{Decision making, diversity, and learning}

Adaptive capacities are enhanced when collaborators find ways to combine diverse perspectives for enhanced learning (Dewulf et al. 2007, Miller et al. 2008). Similar studies of resilience and interdisciplinary collaborations have demonstrated the importance of diversity of perspectives and forging new frames of understanding (Dewulf et al. 2007, Miller et al. 2008) so that sources of creativity can generate new insights about problems. In situations of continual and abrupt change, the diversity of ecologies, livelihoods, perspectives, and the presence of governance that is inclusive have been shown to be essential for resilience (Adger et al. 2005).

Several interview participants described how team structures fostered or inhibited inclusion of diverse perspectives. One researcher described initial meeting strategies that influenced subsequent team collaboration. Initially, this team met face-toface and engaged in extended discussion about methodological differences. This process provided opportunities to ask, "Am I doing this right?" laying the foundation for mutual respect and trust. Meeting face-to-face is a material structure and pattern of action that interacts with a semiotic structure of what is defined as "right" that then guided how the team ordered itself.

This demonstrates the mutual influence of structure and process. The team's use of active listening coupled with reflection on disciplinary differences demonstrated high communication competence (Thompson 2009). This approach enabled identification and negotiation of frame differences and the production of new frames of understanding (Dewulf et al. 2007). This team figured out how to include remote sensing as a research technique by using inclusive decision making as process coupled with meeting face-to-face to work through differences in methods and disciplinary language. These communication interactions then set them on a course to produce specific and measurable outcomes like mutual understanding across disciplines, as collaborators learned more about remote sensing and its value. This team developed strategies to include diverse ideas where remote sensing people could integrate their skill set into the team. Finally, they charted a course to make progress toward the stated goal of promoting the use of remote sensing in Maine communities.

In contrast, teams using a single person decision-making model defined what is "right" within a narrower participation space. Consequently, those who did not have access to that space felt their ideas were excluded from the team's development. When teams do not create space to integrate diverse perspectives, e.g., remote sensing people are not invited to explain the value of their work or graduate students are unable to contribute their expertise, teams constrain their learning opportunities and adaptive capacities.

Team members defined semiotic structures, such as typologies and norms, alongside material structures, including how a team meets and the length and frequency of these meetings. These become paired with processes that further guide what occurs, such as decision making, learning, and the combination of diverse perspectives. Individual, team, and organizational awareness of how these system components interact is essential for team adaptability and functionality. Further, this awareness allows the identification of whether or not interactions are aligned with intended outcomes and creates a basis to make decisions about how to strategically alter specific structures and processes for improved outcomes.

\section{Recursive model of change}

There is a need to understand changes across scales in systems in which interactions among diverse parts produce emergent wholes (Gunderson and Holling 2001). Feedback and recursivity are related yet distinct ways of tracing the part to whole relationship within complex systems. Feedback focuses on how information exchanged between the parts of a system promotes self-regulation for dynamic stability or transformation (Walker et al. 2004, Lebel et al. 2006). Feedback more closely aligns with a cybernetic systems perspective in which humans have a higher degree of assumed control than in complex adaptive systems (Morgan 1997, Ramage and Shipp 2009).

As an alternate yet complementary orientation, recursive models of change assume that systems themselves contain the seeds for their own maintenance and transformation (Giddens 1984, Hernes and Bakken 2003). Recursivity accepts "that structure and process interact, and furthermore, that they both change through mutual interaction" (Hernes \& Bakken 2003:1512). Strategic action as adaptation is still possible but the ability to control is less complete (Giddens 1984), focusing instead on attunement to systems dynamics and attempted alignment. Emphasizing becoming over remaining, what becomes possible is conditioned by what came before; but what emerges is a continually new and redefined pattern of order (Barad 2007). In a recursive model, visualizations that emphasize the fractal or fluid dimensions of change are preferred over those that are based on attractors and basins (Morgan 1997).

We apply the lens of recursivity to the above discussion of diversity, decision making, and learning. When the team we described met face-to-face, they talked about differences in method and developed new frames of understanding for what was "right" (Dewulf et al. 2007). These semiotic and material structures interacted with team-based decision making and communication competence, and the team consequently figured out how to include remote sensing as a technique. We can consider how these patterns of order recursively flowed throughout structures and processes at different organizational scales. Applying our quantitative results to the individual level, the researcher who used remote sensing likely felt involved in the decision making and that her ideas were included. From our qualitative results, we know that having access to decision making influenced how collaborators felt about the team, their ongoing commitment to working together, and their ability to produce sustainability-related outcomes. In this case, the outcome was related to the ability to use remote sensing as a technology for community mapping and sustainable development. These parts, individual, team, organization, SES, are recursively related because what happens at individual and team levels influences what becomes possible and available within organizations and SES, and vice-versa.

In the results related to motivations and identities, the researcher who described the integration of sustainability science into her own identity provides another example of recursion. Opportunities for learning within SSI as an organization, like the many presentations in which participants learned about the work 
of Dickson and others, helped promote sustainability-related identities. For this participant, changing how she saw herself as a scholar has implications for her continued association with the team and the outcomes this team can produce because of her unique contributions. The results from the PCA showed that participants similarly expressed identity as sustainability scientists, a need to span boundaries, and interest in serving society. These identity and motivation patterns are key processes for SSI as an organization if it is to outlive the current grant cycle. Encouraging the development of these patterns as the organization changes will recursively guide the organization for what it continues to become.

\section{Emergent patterns of order}

Resilience literature shows that interactions that promote learning from diversity can enhance creativity, responsiveness, and adaptive capacities. Recursivity assumes interactions are always set within self-similar, nonlinear, and mutually influencing modes of production. Strategic change comes from paying attention to structures and processes that emerge from these interactions and how these shape cross-scale patterns of order.

What matters is not necessarily one meeting strategy or decision making approach over another but attunement to how structures and processes create conditions for what becomes possible in teams and how strategic transformation of these system properties may promote different outcomes. If a team is not making progress toward stated goals, individual members express dissatisfaction with engagement, or collaborators feel they do not understand one another, looking at the processes and structures that influence interactions will help identify ways the team may change. For structure, understanding that the term "stakeholder" is not neutral but rather a set of semiotic associations that order meaning gives team members a concrete point of reflection to make differences clear and to create new frames. One person on a team may narrowly define stakeholders as policy makers where another person defines stakeholder more broadly to include future generations and citizens. Exposing those structural differences provides a starting point for negotiating new structural frames, and, subsequently, enabling the mobilization of diversity for mutual understanding and creative insight.

In terms of process, collaborators need to examine their decision making to ask: Do all participants have access to decision space to potentially influence research design? Do they have a space to articulate their unique contributions and why these may be important to outcomes? They should be aware of communication competence and the ways that embodied interactions, like laughter and listening, promote mutual understanding, among other outcomes. Further, understanding that identities and motivations are adaptive capacities that recur through a system, and continually encouraging identities and motivations that connect with core sustainability goals and values, like boundary spanning and serving society, offers a strategic approach to intentional learning opportunities.

\section{CONCLUSION}

This research identifies important communication dimensions in sustainability science teams as complex systems. We conclude by highlighting four key strategies for analyzing communication within teams and designing process and structure for intended outcomes:
(1) Words, typologies, meeting strategies, and technologies structure participation

Paying attention to communication as semiotic and material structures highlights the multiple ways in which words, typologies, and other norms define participation in teams. Awareness of these structures is critical for identifying and strategically implementing changes that promote inclusiveness and responsiveness to the needs and interests of "stakeholders."

When we accept that multiscalar interactions create social organizations, like sustainability science teams, then it is crucial to pay attention to the microlevel details of interactions. This means we need to recognize structural parts of the system as choices and that we can choose differently should the need arise. For example, labeling someone as a "stakeholder" when they may see themselves a "partner" or "sustainability scientist," can produce conflict and disenfranchisement. Creating opportunities for people to negotiate word choices, frame differences, meeting structures, and the use of communication technologies is essential for recursive alignment within teams as complex systems. At the level of practice, informally collecting information or formally gathering data through surveys and/or interviews about preferences should occur regularly throughout a collaboration.

\section{(2) Decision making matters}

Communication processes that occur within face-to-face meetings compared with e-mail exchanges compared with video conferences may result in similar outcomes. For example, inclusive decision making that allows diverse ideas to be included in the project can occur through e-mail. However, the mutual influence of decision making as process and these structures matters. If a single person on the team defines structure in ways that foreclose others' participation to voice their preferences, team members will not have satisfaction with the process and the team is not likely to make progress toward interdisciplinary, sustainability-related goals.

Decision-making processes are operationalized in a similar way to how structures are defined. Preferences for decision making need to be articulated at the initiation of team formation and then regularly assessed as above. For example, in the beginning stages participants may desire a broader consensus process. As specific tasks develop, they may prefer problem-project specific modes of decision making. In terms of practice, meeting notes should record these preferences and should be shared in ways that allow participants to clarify and add their perspective to the record.

\section{(3) Communication creates relationships and teams; specific communication competencies, like humor, can help intentionally guide both}

Communication includes but also transcends information exchange. Communication shapes our sense of self and our relationships within the world. Accepting that communication creates social organization means that the every interaction matters. This raises individual and team levels of responsibility to attend to communication competencies. Actively seeking out opportunities to bring humor into collaboration does more than insert a moment of laughter: it helps create a social organization in which people have a sense of well-being based in mutual understanding.

If, as sustainability scientists, we want to encourage well-being and better understanding across difference within society, we sow 
the seeds for that within ourselves and on our teams. Practicing active listening, resisting negative sarcasm, and avoiding comments that attempt to position you or your institution in a place of power over another are key commitments to creating a group with high communication competence.

(4) Realizing our goals for sustainability is possible when we attune to communication as a complex system and find ways to promote recursive alignment towards specific outcomes

Approaching communication as a complex system means that our interventions are always incomplete because human interactions are recursively guided by context-specific structures and processes that are always in a state of becoming. Teams that used a single person decision-making model failed to promote mutual understanding and progress toward sustainability goals because this approach closes down opportunities to understand and adjust to the inevitable complexity of communication structures and processes within teams. In contrast, attunement to communication complexity encourages us to pay attention to how structures and process come together to shape outcomes. By approaching communication as complex system, we may identify and nurture interactions and patterns on teams to promote the outcomes we intend for social and ecological sustainability.

Responses to this article can be read online at: http://www.ecologyandsociety.org/issues/responses. $\mathrm{php} / 6644$

\section{Acknowledgments:}

We would like to acknowledge and thank the Sustainability Solutions Initiative faculty and graduate students who contributed their insights to this research. This research was made possible through a National Science Foundation award EPS-0904155 to Maine EPSCOR at the University of Maine

\section{LITERATURE CITED}

Adger, W. N., T. P. Hughes, C. Folke, S. R. Carpenter, and J. Rockström. 2005. Social-ecological resilience to coastal disasters. Science 309(5737):1036-1039. http://dx.doi.org/10.1126/science.1112122

Ballard, H. L., and J. M. Belsky. 2010. Participatory action research and environmental learning: implications for resilient forests and communities. Environmental Education Research 16 (5-6):611-627. http://dx.doi.org/10.1080/13504622.2010.505440

Barad, K. 2007. Meeting the universe halfway: quantum physics and the entanglement of matter and meaning. Duke University Press, Durham, North Carolina, USA. http://dx.doi. org/10.1215/9780822388128

Corbin, J., and A. Strauss. 2008. Basics of qualitative research. Sage, Thousand Oaks, California, USA.

Creswell, J. W. 2003. Research design: qualitative, quantitative and mixed methods approaches. Sage, Thousand Oaks, California, USA.

Daniels, S., and G. B. Walker. 2001. Working through environmental conflict: the collaborative learning approach. Praeger, Westport, Connecticut, USA.
Depoe, S. P., J. W. Delicath, and M. F. A. Elsenbeer. 2004. Communication and public participation in environmental decision making. State University of New York Press, Albany, New York, USA.

Dewulf, A., G. François, C. Pahl-Wostl, and T. Taillieu. 2007. A framing approach to cross-disciplinary research collaboration: experiences from a large-scale research project on adaptive water management. Ecology and Society 12(2): 14. [online] URL: $\underline{\text { http:// }}$ www.ecologyandsociety.org/vol12/iss2/art14/

Dillman, D. A. 2007. Mail and internet surveys: the tailored design method. John Wiley and Sons, Hoboken, New Jersey, USA.

Folke, C., S. R. Carpenter, B. Walker, M. Scheffer, T. Chapin, and J. Rockström. 2010. Resilience thinking: integrating resilience, adaptability and transformability. Ecology and Society 15(4): 20. [online] URL: http://www.ecologyandsociety.org/vol15/iss4/ $\underline{\operatorname{art} 20 /}$

Folke, C., T. Hahn, P. Olsson, and J. Norberg. 2005. Adaptive governance of social-ecological systems. Annual Review of Environment and Resources 30:441-473. http://dx.doi.org/10.1146/ annurev.energy.30.050504.144511

Fraser, H., and A. C. Schalley. 2009. Communicating about communication: intercultural competence as a factor in the success of interdisciplinary collaboration. Australian Journal of Linguistics 29:135-155. http://dx.doi.org/10.1080/07268600802516418

Giddens, A. 1984. The constitution of society: outline of the theory of structuration. University of California Press, Berkley, California, USA.

Goldstein, B. E. 2012. Collaborative resilience: moving through crisis to opportunity. MIT Press, Cambridge, Massachusetts, USA.

Gunderson, L. H., and C. S. Holling. 2001. Panarchy: understanding transformations in human and natural systems. Island Press, Washington, D.C., USA.

Hair, J. F., W. C. Black, B. J. Babin, and R. E. Anderson. 2010. Multivariate data analysis. Seventh edition. Pearson Education Inc., Upper Saddle River, New Jersey, USA.

Hernes, T., and T. Bakken. 2003. Implications of self-reference: Niklas Luhmann's autopoiesis and organization theory. Organization Studies 24(9):1511-1535. http://dx.doi. org/10.1177/0170840603249007

Janssen, M. A. 2013. The role of information in governing the commons: experimental results. Ecology and Society 18(4): 4. http://dx.doi.org/10.5751/ES-05664-180404

Johnson, T., and G. B. Zydlewski. 2012. Research for the sustainable development of tidal power in Maine. Maine Policy Review 21(1):58-64.

Jordan, R. C., H. L. Ballard, and T. B. Phillips. 2012. Key issues and new approaches for evaluating citizen-science learning outcomes. Frontiers in Ecology and the Environment 10 (6):307-309. http://dx.doi.org/10.1890/110280

Kates, R. W., W. C. Clark, R. Corell, J. M. Hall, C. C. Jaeger, I. Lowe, J. J. McCarthy, H. J. Schellnhuber, B. Bolin, N. M. Dickson, S. Faucheux, G. C. Gallopin, A. Grübler, B. Huntley, J. Jäger, N. S. Jodha, R. E. Kasperson, A. Mabogunje, P. Matson, H. Mooney, 
B. Moore III, T. O. Riordan, and U. Svedin. 2001. Sustainability science. Science 292(5517):641-642. http://dx.doi.org/10.1126/ science. 1059386

Lebel, L., J. M. Anderies, B. Campbell, C. Folke, S. HatfieldDodds, T. P. Hughes, and J. Wilson. 2006. Governance and the capacity to manage resilience in regional social-ecological systems. Ecology and Society 11(1): 19. [online] URL: http://www. ecologyandsociety.org/vol11/iss1/art19/

McGreavy, B., K. Hutchins, H. Smith, L. Lindenfeld, and L. Silka. 2013. Addressing the complexities of boundary work in sustainability science through communication. Sustainability 5:4195-4221. http://dx.doi.org/10.3390/su5104195

Miller, T. R., T. D. Baird, C. M. Littlefield, G. Kofinas, F. S. Chapin III, and C. L. Redman. 2008. Epistemological pluralism: reorganizing interdisciplinary research. Ecology and Society 13 (2): 46. [online] URL: http://www.ecologyandsociety.org/vol13/ iss $2 / \operatorname{art} 46 /$

Mitchell, M. 2009. Complexity: a guided tour. Oxford University Press, New York, New York, USA.

Monge, P. R. 1977. The systems perspective as a theoretical basis for the study of human communication. Communication Quarterly 25:19-29. http://dx.doi.org/10.1080/01463377709369244

Morgan, G. 1997. Images of organizations. Sage, Thousand Oaks, California, USA.

Norberg, J., and G. S. Cumming. 2008. Complexity theory for a sustainable future. Columbia University Press, New York, New York, USA.

Norton, T. 2007. The structuration of public participation: organizing environmental control. Environmental Communication 1:146-170. http://dx.doi.org/10.1080/17524030701642546

Pahl-Wostl, C. 2006. The importance of social learning in restoring the multifunctionality of rivers and floodplains. Ecology and Society 11(1): 10. [online] URL: http://www.ecologyandsociety. org/vol11/iss1/art10/

Pahl-Wostl, C., E. Mostert, and D. Tàbara. 2008. The growing importance of social learning in water resources management and sustainability science. Ecology and Society 13(1): 24. [online] URL: http://www.ecologyandsociety.org/vol13/iss1/art24/

Patton, M. Q. 2002. Qualitative research and evaluation methods. Sage, Thousand Oaks, California, USA.

Poole, M. S., and R. D. McPhee. 2005. Structuration theory. Pages 171-196 in S. May and D. K. Mumby, editors. Engaging organizational communication theory and research: multiple perspectives. Sage, Thousand Oaks, California, USA.

Ramage, M., and K. Shipp. 2009. Systems thinkers. Springer, London, UK. http://dx.doi.org/10.1007/978-1-84882-525-3

Schneider, M., and M. Somers. 2006. Organizations as complex adaptive systems: implications of complexity theory for leadership research. Leadership Quarterly 17(4):351-365. http:// dx.doi.org/10.1016/j.leaqua.2006.04.006

Senecah, S. L. 2004. The trinity of voice: the role of practical theory in planning and evaluating the effectiveness of environmental participatory processes. Pages 13-34 in S. P. Depoe, J. W. Delicath, and M.-F. A. Elsenbeer, editors. Communication and public participation in environmental decision making. State University of New York Press, Albany, New York, USA.

Shirk, J. L., H. L. Ballard, C. C. Wilderman, T. Phillips, A. Wiggins, R. Jordan, E. McCallie, M. Minarchek, B. V. Lewenstein, M. E. Krasny, and R. Bonney. 2012. Public participation in scientific research: a framework for deliberate design. Ecology and Society 17(2): 29. http://dx.doi.org/10.5751/ ES-04705-170229

Stokols, D., R. P. Lejano, and J. Hipp. 2013. Enhancing the resilience of human-environment systems: a social-ecological perspective. Ecology and Society 18(1): 7. http://dx.doi. org/10.5751/ES-05301-180107

Thompson, J. L. 2007. Interdisciplinary research team dynamics a systems approach to understanding communication and collaboration in complex teams. VDM Verlag, Saarbrücken, Germany.

Thompson, J. L. 2009. Building collective communication competence in interdisciplinary research teams. Journal of Applied Communication Research 37:278-297. http://dx.doi. org/10.1080/00909880903025911

Vaske, J. J. 2008. Survey research and analysis: applications in parks, recreation and human dimensions. Venture Publishing, State College, Pennsylvania, USA.

Walker, B., C. S. Holling, S. R. Carpenter, and A. Kinzig. 2004. Resilience, adaptability and transformability in social-ecological systems. Ecology and Society 9(2): 5. [online] URL: http://www. ecologyandsociety.org/vo19/iss2/art5/

Walker, G. B., S. L. Senecah, and S. E. Daniels. 2006. From the forest to the river: citizens' views of stakeholder engagement. Human Ecology Review 13:193-202. 